\title{
Ultrasonic and dopplerometric characteristics of chronic endometritis of women with infertility and miscarriage
}

\author{
Elena V. Kozyreva', Natalia A. Tyurina², Natalia A. Andreeva², Inna V. Merenkova³ ${ }^{3}$ Maria A. Kuznetsova ${ }^{3}$
}

\begin{abstract}
Objectives: To determine ultrasonic and dopplerometric characteristics of chronic endometritis of women having reproductive problems before and after offered treatment.

Materials: We have examined 56 patients (the first group) having morphologically verified chronic endometritis and 42 healthy women (the second group) without pregnancy and endometrial interferences in anamnesis. Everybody has been carried out common research such as anamnesis, general and gynecological examination, ultrasonography, dopplerometry. We have also conducted morphological and immunohistochemical research of endometrium's tissue and have taken bacterial seeding from uterine cavity. Patients of the first group received treatment, after this treatment, we have conducted the control ultrasonography and dopplerometry.

Results: Women of the first group have disturbance of endometrium's ultrasonic structure and modification of bloodstream in the fallopian, radial, basale and spiral arteries. After the treatment, the patients with chronic endometritis have an improvement of endometrium's structure and thickness and in the characteristics of bloodstream.

Conclusions: Each woman with chronic endometritis has a modification in ultrasonic and sanguimotory factors of endometrium. With the purpose of determination of the endometrium's state on stage of pre-gravity training sonography and dopplerometry are the necessary methods of research. Offered method is effective in the treatment of chronic endometritis.
\end{abstract}

Keywords: chronic endometritis, infertility, miscarriage, fallopian arteries, radial arteries, basale arteries, spiral arteries, dopplerometry

\section{INTRODUCTION}

Chronic endometritis is one of the most topical problem of modern gynecology, which is one of the reason of reproductive function's disturbance of woman, including miscarriage, infertility, unsuccessful attempts of assisted reproduction's methods (1).

Diagnostics' problems are related to the absence of expressed symptomatology of the disease which causes tardy and incomplete examination. So for precising of the diagnosis such methods are used: ultrasonography, hysteroscopy, histological examination, microbiological examination, immunohistochemical research of endometrium's tissue (2).

Ultrasonic diagnostics of endometritis has several difficulties, which can be explained by specific features of anatomical organization of female breeding organs and also by demerits of the method. Nevertheless, ultrasonic diagnostics is widespread method of non-invasive diagnosis of inflammatory disease of uterus and appendages (3). We can't diagnose the chronic endometritis on the base of only ultrasonic diagnostics, but we can suspect it and produce additional examination (4). So, the process of diagnostics of the chronic endometritis doesn't limit to only one investigation, but supposes combined evaluation of patient's state and the results of the tests. It's necessary to understand that in the case of chronic endometritis ultrasonic diagnostics allows to reveal the inflammatory process so much as its consequences, which are shown as structural and anatomical modifications of uterus. During ultrasonic diagnostics it's absolutely important to determine risk factors, as we can observe different ultrasound features in each specific situation $(5,6)$.

\footnotetext{
1 Ulyanovsk State University, Ulyanovsk, Russia.

2 Ogarev Mordovia State University, Saransk, Russia.

3 The Sechenov First Moscow State Medical University, Moscow, Russia.
}

Correspondence: Elena V. Kozyreva

Ulyanovsk State University, Ulyanovsk, Russia.

Received: 9 Aug 2018, Accepted: 23 Nov 2018

E-mail: miss_smile_777@mail.ru

(C) 2019 by the authors; licensee Modestum Ltd., UK. This article is an open access article distributed under the terms and conditions of the Creative Commons Attribution License (http://creativecommons.org/licenses/by/4.0/). 
Ultrasound features of chronic endometritis were firstly determined in 1993 by Professor V.N. Demidov. The examination is conducted on 5-7 and 17-21 day of menstrual cycle. Uterus' cavity after the menstrual cycle is dilated up to $0.4-0.7 \mathrm{sm}$., sometimes we can see asymmetry of the dilation of uterus' cavity and asperity of endometrium's interface.

Modification of the structure of endometrium is also shown by the appearance of zones of increased echogenicity of different size and form in the point of $\mathrm{M}$-echo and inside of these zones separate sections of incorrect form with decreased echogenicity are fixed. Another important feature of chronic endometritis is the presence of gas bubbles, sometimes with typical acoustic effect. In the basal layer of endometrium, we can often see precise hyperechoic formations up to $0.1-0.2 \mathrm{sm}$. in diameter, which are represented as nidi of fibrosis, sclerosis and calcinosis. Asymmetry of thickness of front and back sides of endometrium is infrequent but important feature of chronic endometritis (7). Sensibility of the method is $78.1 \%$, its specificity $-82.5 \%$ (8).

Except structural modifications chronic endometritis is also shown by the disturbance of hemodynamics in the vessels of uterus and in the vessels of pelvis (9-11). Dopplerometry allows diagnosing these modifications. The disturbance of bloodstream in the vessels of uterus with the predominance of damage on the level of basale and spiral arteries, and also the difficulties of visualization of terminal artery shows the great disturbance of tissue's perfusion on account of chronic inflammatory process.

\section{METHODOLOGICAL FRAMEWORK AND METHODS}

For the purpose of study of ultrasonic and dopplerometric characteristics of pelvis' organs of patients having chronic endometritis we have examined 56 patients (the first group, at the age of 29,0 $\pm 0,24$ ) with morphologically verified chronic endometritis, who have seen the doctor at PHI «Ulyanovsk Regional Clinical Hospital» in Ulyanovsk in 2016-2017 with the object of pregnancy planning. As a group of comparison (the second group, at the age of $30.0 \pm 0.4$ ) we have examined 42 healthy women without pregnancy and endometrial interferences in anamnesis, who have seen the doctor to receive the help on the programs of assisted reproduction's methods because of male infertility.

Everybody has been carried out common research such as anamnesis and general and gynecological examination.

We conducted ultrasonic examination of pelvis' organs of women of the first group before and after the treatment. We conducted ultrasonic examination of patients of the second group once on the apparatus Voluson E6 and Voluson E8 (General Electric, USA) using multifrequency transvaginal sensor with frequence of $8 \mathrm{MHz}$. We have conducted ultrasonic examination on 20-24 day of menstrual cycle. We began the examination by conducting the transabdominal scanning (with full urinary bladder) for the purpose of excluding volumetrical pathology of pelvis' cavity, we determined its form, the structure of myometrium and excluded miomatous and adenomyosis.

We focused special attention to M-echo: its thickness, echo-structure and presence of formations. Normal features of $\mathrm{M}$-echo are homogeneous structure, absence of hypo- or hyperechogenic formations, accordance of its structure to the day of menstrual cycle, the thickness of M-echo at least $8 \mathrm{ml}$.

During dopplerometry of uterus' vessels we determined the bloodstream in the right and the left uterus' arteries according to following figures: index of resistance, index of pulsation, systolic-diastolic ratio, maximum rate of bloodstream in phase of systole (Vps). Subjective estimation of the level of vascularization included also the determination of bloodstream in radial, basale arteries and spiral arteries.

The final diagnosis of chronic endometritis was determined on the base of morphological study of endometrium, taken on 7-11 day of menstrual cycle using paypel-biopsy or aspirating biopsy of endometrium. Morphological criteria for such diagnosis are the following: inflammatory infiltration, consisting of lymph cells, neutrophilic leukocytes settled most often around the glands and blood vessels, rarely diffusely; presence of plasma cells; alteration of endometrium's stroma, including fibrosis; sclerous modification of spiral arteries; deformation of glands; focal hyperplasia of basal layer.

We have also conducted immunohistochemical research of endometrium's tissue with the help of the method of peroxidase technique on the paraffin sections 3-4 $\mu \mathrm{m}$. of thickness. Bacterial seeding from uterine cavity has been obligatory taken.

Patients of the first group received the treatment: immunomodulatory, metabolic, therapy directed to improvement of microcirculation in the endometrium, hormone therapy (the drug of progesterone in the second phase of menstrual cycle), combined oral contraceptives, antiviral treatment, nonsteroidal anti-inflammatory drugs, physiotherapy.

We started the treatment from the first day of menstrual cycle. We used combined oral contraceptives only identifying hyperplasia of endometrium without atypia. We prescribed combined oral contraceptives with antiandrogenic effect only to women who have weak and moderate expression of the androgen receptors in the endometrium, which was determined due to immunohistochemical research (12-15). 
Table 1: Results of dopplerometry of uterine's vessels of fertile women of the second group $(n=42)$

\begin{tabular}{ccccc}
\hline Blood flow indicator & Fallopian arteries & Radial arteries & Basale arteries & Spiral arteries \\
\hline Vps $(\mathrm{m} \backslash \mathrm{s})$ & $0.51 \pm 0.12$ & $0.09 \pm 0.03$ & $0.06 \pm 0.03$ & $0.04 \pm 0.03$ \\
\hline systolic-diastolic ratio & $5.2 \pm 2.34$ & $3.14 \pm 0.67$ & $2.3 \pm 0.57$ & $1.8 \pm 0.56$ \\
\hline index of pulsation & $1.81 \pm 0.54$ & $1.23 \pm 0.39$ & $0.92 \pm 0.09$ & $0.88 \pm 0.09$ \\
\hline index of resistance & $0.79 \pm 0.06$ & $0.77 \pm 0.09$ & $0.72 \pm 0.07$ & $0.58 \pm 0.17$ \\
\hline
\end{tabular}

In the case of hypoplastic endometrium the treatment was conducted by oral and transdermal estrogens since 5 to 21 day of menstrual cycle. In the case of the absence of adequate corrective influence to the endometrium we used intravenous drip of placenta hydrolyzate (drug Laennec). Without effect we used suppositories (drug Viagra) and a complex physiotherapy.

Hysteroresectoscopy was conducted in the case of polyp of endometrium with subsequent drug therapy.

Autoplasma therapy, which was conducted after the completion of menstrual bleeding at intervals of 5 days by injection in the vaginal vaults, became an effective treatment.

Antibiotics were prescribed only in the case of conditionally pathogenic microflora after the determining its drug sensitivity.

We picked out such drugs: tetracycline and penicillin with a broad spectrum of action with beta-lactamase inhibitor. In physiotherapy we used diode laser «Matrix» of red spectrum.

The total treatment lasted 3 months.

After this treatment, we conducted ultrasonic examination of pelvis' organs on 20-24 day of menstrual cycle to determine the endometrium. The criteria of an effective treatment are the following: an appropriate transformation of endometrium, the presence of «three-layer», the presence of ovulation during this menstrual cycle.

We conducted the control dopplerometry to all women of the first group.

All women gave an agreement to use the information about their medical examination for scientific purposes. The research is done in compliance with the Helsinki Declaration on the examination and treatment of people. Also, it was approved by ethics Committee of Ulyanovsk State University.

\section{RESULTS AND DISCUSSION}

Bacteriological tests of aspirates from the uterine cavity of all healthy women and $52(92.9 \pm 3.5 \%)$ patients having chronic endometritis $(p<0.001)$ didn't identify microflora growth. Other women of the first group had Escherichia coli.

As a result of histological and immunohistochemical tests we received the following facts: $12(21.4 \pm 5.5 \%)$ women of the first group had moderately expressed chronic endometritis with the presence of polyps or endometrial hyperplasia without atypia. We identified an expressed chronic inflammation of endometrium only in the presence of polyps, and 4 (7.1 $\pm 3.5 \%)$ patients of the first group had such diagnosis. All the women of the second group didn't have any pathology of endometrium $(p<0.05)$.

Women with chronic endometritis have disturbance of expression of the receptors to estrogens as in stroma as in cells' nucleus more often than patients of the second group. Women with chronic endometritis had the disturbance of expression of the receptors to progesterone rarely, it was identified in stroma in most cases. Only women of the first group, $12(21.4 \pm 5.5 \%)$ had the disturbance of expression of androgenic receptors in the endometrium. The patients of the second group didn't have such disturbance $(p<0.001)$.

Inflammatory reaction in the endometrium of women having reproductive problems was shown basically as lymphocytic infiltration and was represented by CD3, CD4, CD8 lymphocytes. Patients with chronic endometritis 20 $(35.7 \pm 6.5 \%)$ didn't have plasma cells. We considered the presence of lymphocytic infiltration in stroma of endometrium without plasma cells as incomplete chronic endometritis. In these cases we conducted a complex therapy to all women.

Patients having reproductive problems $14(25.0 \pm 5.8 \%)$ had the disturbance of expression of proliferative activity marker ki-67. Healthy women didn't have this disturbance $(p<0.001)$.

We made a comparative assessment of data taken from the results of ultrasonic and dopplerometric research before and after complex treatment.

Women of the second group had endometrial thickness of $10.3 \pm 0.4 \mathrm{ml}$. (from $8.7 \mathrm{ml}$ to $12.3 \mathrm{ml}$ ). M-echo was identified as homogeneous structure and corresponded to the second phase of menstrual cycle. Visualization of main bodies of fallopian, radial, basale arteries was possible for all women, the visualization of spiral arteries was possible for $80 \%$ patients (Table 1). 
Table 2: Results of dopplerometry of uterine's vessels of fertile women of the first group $(n=56)$

\begin{tabular}{ccccc}
\hline Blood flow indicator & Fallopian arteries & Radial arteries & Basale arteries & Spiral arteries \\
\hline Vps $(\mathrm{m} \backslash \mathrm{s})$ & $0.43 \pm 0.12$ & $0.03 \pm 0.03$ & $0.01 \pm 0.03$ & $0.01 \pm 0.03$ \\
\hline systolic-diastolic ratio & $9.2 \pm 1.9$ & $5.12 \pm 0.77$ & $4.28 \pm 0.37$ & $3.8 \pm 0.57$ \\
\hline index of pulsation & $1.73 \pm 0.51$ & $1.15 \pm 0.39$ & $0.82 \pm 0.09$ & $0.79 \pm 0.07$ \\
\hline index of resistance & $0.88 \pm 0.05$ & $0.84 \pm 0.09$ & $0.82 \pm 0.07$ & $0.65 \pm 0.14$ \\
\hline
\end{tabular}

Table 3: Results of dopplerometry of uterine's vessels of fertile women of the first group after the treatement $(n=42)$

\begin{tabular}{ccccc}
\hline Blood flow indicator & Fallopian arteries & Radial arteries & Basale arteries & Spiral arteries \\
\hline Vps & $0.50 \pm 0.9$ & $0.04 \pm 0.02$ & $0.06 \pm 0.02$ & $0.03 \pm 0.04$ \\
\hline systolic-diastolic ratio & $6.8 \pm 1.2$ & $4.01 \pm 0.61$ & $3.1 \pm 0.31$ & $2.12 \pm 0.58$ \\
\hline index of pulsation & $1.75 \pm 0.42$ & $1.21 \pm 0.22$ & $0.81 \pm 0.08$ & $0.89 \pm 0.06$ \\
\hline index of resistance & $0.91 \pm 0.05$ & $0.70 \pm 0.01$ & $0.79 \pm 0.07$ & $0.50 \pm 0.13$ \\
\hline
\end{tabular}

Women with chronic endometritis had endometrial thickness of $5.1 \pm 0.34$ (from 3.1 to $6.1 \mathrm{~mm}$ ). Endometrium's structure corresponded to the phase of menstrual cycle in 14 cases $(25.0 \%$ cases). Visualization of main bodies of fallopian, radial arteries was possible for all women, the visualization of basale arteries was possible for 46 women (82.0\%), the visualization of spiral arteries was possible for 14 patients (25.0\%).

The patients of the first group had modifications of the bloodstream in fallopian, radial, basale and spiral arteries, this fact confirms the disturbance tissue perfusion in the uterus (Table 2).

Women with chronic endometritis had expressed modifications in the form of absence of diastolic component.

Estimating the results of the therapy of women of the first group, we made the following conclusions. Endometrial thickness expanded and became $7.6 \pm 0.2 \mathrm{sm}$. for women of the first group. The quantity of patients having hyperechoic formations in it was reduced. The structure of endometrium also changed, it became homogeneous and three-layer in most cases.

Uneven contour of endometrium, inequality of lines of closing of the front and back positions of endometrium were identified rarely. Dopplerometry showed (Plate 3) increase of $\mathrm{Vp} / \mathrm{s}$ after the treatment in fallopian and basale arteries. Systolic-diastolic ratio declined. In assessing subjectively the degree of vascularization we identified an increase of frequency of visualization of basale arteries of 54 women $(96.4 \pm 2.5 \%)$, and spiral arteries of 44 women $(78.6 \pm 5.5 \%)$.

Positive dynamics of index of pulsation and index of resistance was identified only in spiral and radial arteries. It indicates the disturbance of hemodynamic of women of the first group even after the treatment.

\section{CONCLUSION AND RECOMMENDATIONS}

According to received results, all women with chronic endometritis have the disturbance of hemodynamic in the pelvic cavity, so at the stage of pregnancy preparation all patients with histologically confirmed chronic endometritis need sonography and dopplerometry.

Applying in complex of immunomodulatory and metabolic effect directed to the improvement of microcirculation in the endometrium, in the therapy of chronic endometritis allows normalizing the structure of endometrium.

After the treatment, we identified modifications in the ultrasonic indicators of hemodynamic of endometrium of women with chronic endometritis, which attest the possibility of using of dopplerometry as a criterion of assessment of efficiency of medication treatment of women having chronic endometritis.

\section{REFERENCES}

1. Radzinsky BE, Makletsova SA, Aleev IA, Rudnev OD, Ryabinkina TS. Undeveloped pregnancy. Guidelines for MARS (Interdisciplinary Association of Reproductive Medicine Professionals). Moscow: Editorial staff of StatusPraesens magazine, 2015. PMid:25308206

2. Kozyrev EV, Davidyan BJ. Immunohistochemical features of chronic endometritis with infertility and miscarriage. Proceedings of higher educational institutions. Volga region. Medical sciences. 2015;36(4):124-36.

3. Devyatova EA, Tsaturova KA, Vartanyan EV. Predicting of successful implantation at IVF cycles. Gynecol Endocrinol. 2016;2(32):27-9. https://doi.org/10.1080/09513590.2016.1232803 PMid:27759452

4. Imaduddin F, Selezneva NA. Algorithms for the diagnosis of chronic endometritis. Young Scientist. 2016;22:5-8. Retrieved from https://moluch.ru/archive/126/35093/ 
5. Zhang T, He Y, Wang Y, Zhu Q, Yang J, Zhao X, Sun Y. The role of three-dimensional power Doppler ultrasound parameters measured on $\mathrm{hCG}$ day in the prediction of pregnancy during in vitro fertilization treatment. Eur. J. Obstet. Gynecol. Reprod. Biol. 2016;203:66-71. https://doi.org/10.1016/j.ejogrb.2016.05.016 PMid:27254812

6. Li Z, Wang X, Guan Y, Yu X, Liu J, Zhang Z. Uterine artery blood flow and microvessel density by vaginal color Doppler ultrasonography in embryo implantation failure. Exp. Ther. Med. 2017;5(14):4797-800. https://doi.org/10.3892/etm.2017.5114

7. Ozerskaya IA, Semileova AA, Kazaryan GG. Ultrasound diagnosis of endometritis (B-mode). Ultrasound and functional diagnostics. 2017;6:36-52.

8. Bochkov VV, Plekhanov AN, Tsydenova TsB. Chronic nonspecific endometritis: epidemiology, etiology, pathogenesis, risk factors, diagnostics. Bulletin of the Buryat State University. 2015;12:30-38.

9. Plyasunova MP, Khlybova SV, Chicherina EN. Comparative evaluation of ultrasound and Doppler parameters in chronic endometritis. Ultrasound and Functional Diagnostics. 2014;2:56-74.

10. Kim A, Jung H, Choi WJ, Hong SN, Kim HY. Detection of endometrial and subendometrial vasculature on the day of embryo transfer and prediction of pregnancy during fresh in vitro fertilization cycles. Taiwan J. Obstet. Gynecol. 2014;3(53):360-5. https://doi.org/10.1016/j.tjog.2013.05.007 PMid:25286791

11. Gaidarova AKh, Kul'chitskaia DB, Sycheva Alu., Alisultanova LS, Kotenko NV, Tarasova Tlu. Dynamics of the functional characteristics of the microcirculation system in the women of late reproductive age presenting with chronic endometritis under effect of contrast massage. Vopr. Kurortol. Fizioter. Lech. Fiz .Kult. 2014;4:33-7.

12. Kozyreva EV, Davidyan LYu, Kometova VV. Modern approach to the integrated treatment of chronic endometritis in women with infertility and miscarriage. Health and Education in the XXI century. 2016;18(9):11-4.

13. Kuznetsova MA, Miroshkin DV, Timofeeva MO. Morphological and morphometric characteristics of lymphoid structures in the walls of fallopian tubes in postnatal ontogenesis. Giornale Italiano di ostetricia e ginecologia. 2018;1:42-7.

14. Kuznetsova MA, Miroshkin DV, Chilingaridi SN. The content of reticulocytes in the secondary folds of the mucous membrane of the fallopian tubes in women. Morphology. 2017;151(3):80-93.

15. Kuznetsova MA, Miroshkin DV, Chilingaridi SN. Characteristic features of diffuse lymphoid tissue of the mucous membrane of the human fallopian tube Morphology. 2017;151:80-1.

$\diamond \diamond \diamond \diamond \diamond \diamond \diamond$

http://www.ejgm.co.uk 